\title{
An Integrated and Automated Tool for Quantification of Biomechanics in Fetal and Neonatal Echocardiography
}

\author{
Brett A. Meyers Ph.D. ${ }^{1}$, Melissa C. Brindise Ph.D. ${ }^{1}$, R. Mark Payne M.D. ${ }^{2}$, Pavlos P. Vlachos \\ Ph.D. ${ }^{1}$ \\ meyers18@purdue.edu,mbrindis@purdue.edu,rpayne@iu.edu,pvlachos@purdue.edu \\ ${ }^{1}$ School of Mechanical Engineering, Purdue University, West Lafayette, IN, 47907 \\ ${ }^{2}$ Indiana University School of Medicine, Pediatrics, Pediatric Cardiology, Indianapolis, IN, \\ 46202
}

Corresponding Author: Pavlos P. Vlachos, 585 Purdue Mall, West Lafayette, IN, 47907, none, pvlachos@purdue.edu

Total word count: 4057

Funding: This project was supported, in part, by the Indiana Clinical and Translational Sciences Institute funded, in part, by Grant Number UL1TR002529 from the National Institutes of Health, National Center for Advancing Translational Sciences, Clinical and Translational Sciences Award. The content is solely the responsibility of the authors and does not necessarily represent the official views of the National Institutes of Health. No industry partnerships collaborated on or funded this work. 
medRxiv preprint doi: https://doi.org/10.1101/2020.10.21.20217265; this version posted June 22, 2021. The copyright holder for this preprint (which was not certified by peer review) is the author/funder, who has granted medRxiv a license to display the preprint in perpetuity.

\section{$\underline{\text { Abstract }}$}

Background Quantifying ventricular biomechanics from fetal and neonatal echocardiograms presents unique and significant challenges. A new analysis workflow has been introduced for simultaneous quantification of flow and mechanics of cardiac function using an integrated set of automated, physics-based, echocardiography analysis methods.

Methods We used in-house developed analysis algorithms to quantify ventricular biomechanics from four-chamber B-mode and color Doppler routine examination recordings for three hypoplastic left heart (HLHS) patients at 33-weeks' gestation and first week post-birth along with age-matched controls. Chamber morphology, tissue motion, atrioventricular valve inflow, and hemodynamic flow parameters were measured.

Results Prenatal cardiac output differed between control (LV:157 $\pm 139 \mathrm{~mL} / \mathrm{min}, \mathrm{RV}: 257 \pm$ $218 \mathrm{~mL} / \mathrm{min})$ and HLHS subjects $(410 \pm 128 \mathrm{~mL} / \mathrm{min})$. This difference persisted for control $(\mathrm{LV}: 233 \pm 74 \mathrm{~mL} / \mathrm{min}, \mathrm{RV}: 242 \pm 140 \mathrm{~mL} / \mathrm{min})$ and HLHS subjects $(637 \pm 298 \mathrm{~mL} / \mathrm{min})$ after birth. In utero peak early diastolic annulus velocity, e', was elevated in HLHS subjects $(R V: 1.88 \pm 0.97 \mathrm{~cm} / \mathrm{s})$ compared to controls $(\mathrm{LV}: 1.23 \pm 0.81 \mathrm{~cm} / \mathrm{s}, \mathrm{RV}: 1.19 \pm 0.57 \mathrm{~cm} / \mathrm{s})$. After birth $\mathrm{e}^{\prime}$ increased in control RVs $(1.80 \pm 0.73 \mathrm{cms})$ compared to control LVs $(1.26 \pm 0.50 \mathrm{~cm} / \mathrm{s})$ and HLHS RVs $(1.18 \pm 1.12 \mathrm{~cm} / \mathrm{s})$. Postnatal early filling mitral flow velocity for the control subjects (LV:58.8 $\pm 17.6 \mathrm{~cm} / \mathrm{s})$ and early-filling tricuspid flow of the HLHS subjects $(64.8 \pm$ $23.7 \mathrm{~cm} / \mathrm{s}$ ) were similar, while the late filling velocity decreased for the control subject LV $(33.5 \pm 8.1 \mathrm{~cm} / \mathrm{s})$ compared to the HLHS subjects $(66.9 \pm 23.0 \mathrm{~cm} / \mathrm{s})$. Importantly, flow energy loss in the fetal HLHS hearts was increased $\left(0.35 \pm 0.19 \mathrm{~m}^{3} / \mathrm{s}^{2}\right)$ compared to the control subjects $\left(\mathrm{LV}: 0.09 \pm 0.07 \mathrm{~m}^{3} / \mathrm{s}^{2}, \mathrm{RV}: 0.17 \pm 0.12 \mathrm{~m}^{3} / \mathrm{s}^{2}\right.$ ), and further increased postnatally for the HLHS subjects $\left(0.55 \pm 0.24 \mathrm{~m}^{3} / \mathrm{s}^{2}\right)$ compared to the control subjects (LV:0.23 $\pm 0.20 \mathrm{~m}^{3} / \mathrm{s}^{2}$, $R V: 0.09 \pm 0.06 \mathrm{~m}^{3} / \mathrm{s}^{2}$ ).

Conclusions We demonstrate the feasibility of integrated quantitative measurements of fetal and neonatal ventricular hemodynamics and biomechanics using only four-chamber B-mode and color Doppler recordings.

Keywords: fetal ultrasound, pediatric ultrasound, image processing, vector flow mapping 
medRxiv preprint doi: https://doi.org/10.1101/2020.10.21.20217265; this version posted June 22, 2021. The copyright holder for this preprint (which was not certified by peer review) is the author/funder, who has granted medRxiv a license to display the preprint in perpetuity.

All rights reserved. No reuse allowed without permission.

Abbreviations

$\mathrm{AV}=$ Atrioventricular

ALAX = Apical long axis

$\mathrm{CHD}=$ Congenital heart disease

$\mathrm{CFI}=$ color flow imaging

$\mathrm{CO}=$ Cardiac output

$\mathrm{ECG}=$ Electrocardiogram

$\mathrm{EL}=$ Energy loss

HLHS = Hypoplastic Left Heart Syndrome

$\mathrm{LV}=$ Left ventricle

$\mathrm{RV}=$ Right ventricle

$\mathrm{VS}=$ Vortex strength

$\mathrm{SV}=$ Stroke volume

$\Delta P=$ Pressure difference 
medRxiv preprint doi: https://doi.org/10.1101/2020.10.21.20217265; this version posted June 22, 2021. The copyright holder for this preprint (which was not certified by peer review) is the author/funder, who has granted medRxiv a license to display the preprint in perpetuity.

\section{$\underline{\text { Introduction }}$}

Amidst four million children born yearly in the United States, nearly $1 \%$ suffer a congenital heart defect $(\mathrm{CHD})^{1,2}$, with annual treatment costs exceeding $\$ 6$ billion $^{3}$ and median survival age of 1 year ${ }^{4}$. Detecting CHDs with fetal ultrasound enables earlier care planning, improving outcomes and costs ${ }^{5}$. Still, accurate diagnosis in utero remains a challenge, with top specialists detecting slightly more than $50 \%$ of $\mathrm{CHDs}^{6}$, specialty hospitals detecting $35 \%$, and community hospitals detecting just $13 \%{ }^{7}$.

Fetal ultrasound is mainly assessed qualitatively, with the latent ability to quantify basic cardiac biometric and function parameters (i.e. chamber dimensions, stroke volume (SV), cardiac output $(\mathrm{CO}))^{8,9}$. These parameters are measured manually, producing subjective results dependent on expertise and training ${ }^{8}$. Additionally, low image resolution, imaging depth, irregular position, heart size, and motion influence their accurate measurement ${ }^{9}$. In cases of suspected defects and high-risk pregnancies, fetal echocardiography is used to detect CHDs ${ }^{6}$.

Fetal echocardiography collects clinically relevant parameters, including B-mode based strain $^{8}$ and hemodynamics from pulse-wave Doppler ${ }^{9}$. Clinical acceptance of strain measurements lags since they are vendor-specific, and frame rates and image resolution reduce accuracy. Pulse-wave Doppler does not resolve flow-induced vortices and cannot measure energy losses or pressure distributions. Advancements in 4D MRI are improving fetal heart assessment capabilities ${ }^{10}$, but flow imaging has only been studied in animals to date ${ }^{11}$. Significant motion, lack of ECG gating, and low image resolution similarly affect 4D MRI imaging. Currently, there is no integrated methodology capable of quantifying chamber shape, tissue deformation, and hemodynamics jointly and comprehensively from fetal scans.

This study applies an integrated and automated echocardiography analysis method for the measurement of cardiac biomechanics from fetal and neonatal echocardiograms. The analysis combines chamber, annular motion, and hemodynamics quantification. The employed tools are not based on machine learning or shape models, are not vendor-specific, and do not rely on heuristics adopted from adult echocardiography. These advancements uniquely enable the adoption of these tools for routine echocardiogram analysis.

Here, we present the methodology and demonstrate its feasibility and clinical utility in a cohort of hypoplastic left heart syndrome (HLHS) subjects and age-matched controls. We quantified the biomechanics of the left (LV) and right ventricle (RV) in control subjects and 
medRxiv preprint doi: https://doi.org/10.1101/2020.10.21.20217265; this version posted June 22, 2021. The copyright holder for this preprint (which was not certified by peer review) is the author/funder, who has granted medRxiv a license to display the preprint in perpetuity.

All rights reserved. No reuse allowed without permission.

compared them against the HLHS right ventricle. The HLHS presents a demonstratively challenging clinical scenario that punctuates the robustness and capability of the proposed method.

\section{Methods}

\section{Study population}

Twelve examinations were retrospectively selected from within the Indiana University Health network. The cohort comprised three HLHS subjects and corresponding age-matched controls, with fetal exams performed at an average gestational age of 33 weeks and neonatal exams in the first week of birth. All examinations were performed routinely. Datasets without B-mode and color flow imaging (CFI) recordings in the apical long-axis (ALAX) view were excluded. All identifying information was removed from scans prior to data sharing between institutions. The Institutional Review Board for Human Studies for Purdue and Indiana universities approved the study.

\section{Echocardiography}

Sonographers performed fetal echocardiograms on Acuson SC200 ultrasound systems (Siemens Medical Solutions USA, Inc., Malvern, Pennsylvania) with Siemens 6C1 or 4V1 curved-array transducers. Sonographers performed neonatal echocardiograms on either iE33 (Philips, Andover, Massachusetts) or Acuson SC2000 (Siemens Medical Solutions USA, Inc., Malvern, Pennsylvania) ultrasound systems. Recordings taken on iE33 systems used S12-4 phased-array transducers, while those taken on Acuson SC200 systems used 8V3 or 10V4 phased-array transducers. American Society of Echocardiography guidelines were followed ${ }^{9,12}$.

\section{Image analysis workflow}

The analysis workflow, summarized in Figure 1, outputs cardiac biomechanics measurements of the LV and RV from B-mode and CFI ALAX recordings. These modalities are utilized because sonographers are well-trained in their recording, which enhances analysis consistency. The workflow automates measurements, enabling once challenging and highly user-variable analysis to become routine. All algorithms run in MATLAB (The MathWorks, Natick, Massachusetts). 
medRxiv preprint doi: https://doi.org/10.1101/2020.10.21.20217265; this version posted June 22, 2021. The copyright holder for this preprint (which was not certified by peer review) is the author/funder, who has granted medRxiv a license to display the preprint in perpetuity.

\section{Step 1: Tracking user input annulus and apex positions}

One set of user inputs marking the ventricle apex and atrioventricular (AV) annulus positions on the first recorded frame, depicted in Figure 1-1, are required for each scan. These inputs are tracked temporally using a speckle tracking algorithm, described in Appendix A. The tracked positions provide measurements of ventricle relaxation.

AV annulus positions are differentiated temporally to obtain velocities and adjusted relative to the apex, which is assumed stationary during the heartbeat. Peak annulus velocities for systolic ejection ( $\left.\mathrm{s}^{\prime}\right)$, early diastolic filling (e'), and late diastolic filling (a') are automatically measured. Automated speckle tracking mitral annulus position and velocity measurements has been previously validated $^{13}$.

\section{Step 2: Unsupervised chamber segmentation}

Chamber segmentation is uncommon in fetal echocardiography due to poor recording quality, resolution, and model assumptions ${ }^{8}$. Even so, Simpson's rule for volume estimation from fetal imaging has shown good accuracy compared to high fidelity tools ${ }^{14,15}$ and is an accepted tool in neonatal imaging ${ }^{16}$. Measurements are hand-drawn and undergo correction, which increases observer variability, user time, and requires specialized training.

The unsupervised segmentation tool (ProID) automates ventricle detection and volume estimation. The tool identifies ventricle boundaries using an iterative Dijkstra's algorithm ${ }^{17}$, which finds the shortest path of pixels around the ventricle image, shown in Figure 1-2. ProID overcomes contrast-to-noise and resolution limitations that are common in natal imaging ${ }^{18}$ by employing an echocardiogram-specific cost-matrix. The tracked positions are used to initialize ProID for each frame. Further description is provided in Appendix A. The segmentations are processed using Simpson rule to quantify volume. End diastolic volume (EDV) and end-systolic volume (ESV) are output along with SV and CO, which quantify systolic function.

\section{Step 3: Color Flow Imaging hemodynamics analysis}

CFI is used clinically to detect septal and valve defects. Abnormal flow patterns are present in fetuses with $\mathrm{CHDs}^{8}$, which can improve detection when using quantitative tools. Doppler vector reconstruction, or DoVeR, resolves the underlying 2D velocity vector field of blood flow within the ventricle from CFI using the relationship between blood flow rate and fluid rotation ${ }^{19}$. DoVeR uses the tracked positions and ProID to segment the ventricle in each frame. These segmentations are used to set initial conditions for the DoVeR algorithm, shown in Figure 1-3. 
medRxiv preprint doi: https://doi.org/10.1101/2020.10.21.20217265; this version posted June 22, 2021. The copyright holder for this preprint (which was not certified by peer review) is the author/funder, who has granted medRxiv a license to display the preprint in perpetuity.

All rights reserved. No reuse allowed without permission.

The vector fields are evaluated for peak early (E) and late (A) filling velocities, flow energy loss (EL) and vortex strength (VS) as well as the annulus-to-apex suction pressure (suction $\Delta P$ ), pressure recovery (recovery $\Delta P$ ), ejection pressure (ejection $\Delta P$ ), and $\mathrm{AV}$ valve center to minimum pressure $\left(\mathrm{AV}\right.$-to- $\left.\mathrm{P}_{\min }\right)$ distance from computed pressure fields. Further description of DoVeR and pressure field reconstruction are provided in Appendix A.

\section{Statistical Analysis}

Data are reported as mean \pm SD. We compared each parameter across conditions and ages using the paired Student's T-test. A two-tailed p-value $<0.05$ was considered statistically significant. We performed statistical analysis using the MATLAB Statistics toolbox.

\section{$\underline{\text { Results }}$}

\section{Visualization and subject characterization}

Figure 2 displays single beat ventricle volumes from a control fetal subject, a control neonatal subject, and one HLHS subject from their fetal and neonatal echocardiograms. The control LV and RV are shown in blue and red, respectively. The HLHS RV is shown in purple.

In control subjects, the ventricles shorten from end diastole (Figure 2a-1 and 2b-1) to end systole (Figure 2a-2 and 2b-2) as the AV annulus moves, ejecting blood during systole. Fetal EDV (RV: $2.99 \mathrm{~mL}, \mathrm{LV}: 2.75 \mathrm{~mL}$ ) and SV (RV: $0.80 \mathrm{~mL}, \mathrm{LV}: 1.11 \mathrm{~mL}$ ) are similar (Figure 2a3). Neonatal EDV (RV: $5.94 \mathrm{~mL}, \mathrm{LV}: 5.71 \mathrm{~mL}$; Figure 2b-3) and SV (RV: $2.50 \mathrm{~mL}, \mathrm{LV}: 2.55$ $\mathrm{mL})$ measurements between ventricles were similar.

For the HLHS subject, the RV (Figure 2c-1 and 2d-1) occupies the region of both ventricles in controls. This morphology change produces a volume increase compared to the normal RV and allows for changes in hemodynamics. The fetal echocardiogram SV was $2.72 \mathrm{~mL}$ (Figure 2c-3), which increased to $3.61 \mathrm{~mL}$ (Figure 2d-3) by the neonatal exam.

Figure 3 shows single beat flow reconstruction vector fields overlaid onto EL and pressure field reconstructions with closed contours of identified vortices. Results are presented for a fetal control subject, a neonatal control subject, and one HLHS subject from their fetal and neonatal echocardiograms. Frames at diastolic filling and systolic ejection are provided.

Diastolic filling occurs when blood flows into the ventricles through the AV valves, forming a shear region with increased EL and a vortex pair. The fetal LV (Figure 3a-1, right) EL is lower compared to the RV (left), while vortex pairs are present in both ventricles (Figure 3c-1). The 
medRxiv preprint doi: https://doi.org/10.1101/2020.10.21.20217265; this version posted June 22, 2021. The copyright holder for this preprint (which was not certified by peer review) is the author/funder, who has granted medRxiv a license to display the preprint in perpetuity.

neonate (Figure 3a-3) shows similar EL characteristics to the fetal subject with no distinct vortex pairs (Figure 3c-3). The fetal HLHS RV (Figure 3b-1) EL is elevated compared to the control RV with a vortex pair (Figure 3d-1). The neonatal HLHS RV (Figure 3b-3) EL is elevated and a vortex pair present (Figure 3d-3) with smaller energy-inefficient vortices.

Systolic ejection occurs when blood flows from the ventricle through the outflow tract. The fetal RV (Figure 3a-2, left) and neonatal RV (Figure 3a-4, left) show elevated EL along the outflow compared to the LV outflow. Both the HLHS fetal RV (Figure 3b-2) and neonatal RV (Figure 3b-4) outflow tracts are out of view.

\section{Statistical Analysis}

\section{Systolic function}

Measured parameters for the control and HLHS hearts are provided in Figure 4. We observed increased SV in fetal HLHS subjects $(2.40 \pm 0.71 \mathrm{~mL})$ compared against the control LV $(0.97 \pm 0.81 \mathrm{~mL})$ and $\mathrm{RV}(1.72 \pm 1.37 \mathrm{~mL})$. This continued after birth, with neonatal HLHS $\mathrm{SV}(4.50 \pm 2.32 \mathrm{~mL})$ doubling the control LV $(2.37 \pm 0.91 \mathrm{~mL})$ and RV $(2.45 \pm 1.45 \mathrm{~mL})$ Fetal HLHS subject CO $(410 \pm 128 \mathrm{~mL} / \mathrm{min})$ was elevated compared to the control LV $(157 \pm$ $139 \mathrm{~mL} / \mathrm{min})$ and RV (257 $\pm 218 \mathrm{~mL} / \mathrm{min})$. Similarly, neonatal HLHS subject CO (637 \pm 298 $\mathrm{mL} / \mathrm{min}$ ) remained elevated compared to the control LV (233 $\pm 74 \mathrm{~mL} / \mathrm{min})$ and RV (242 \pm 140 $\mathrm{mL} / \mathrm{min}$ ). The metrics indicate the HLHS heart adapts in utero to accommodate added blood volume.

Peak s' velocities in fetal HLHS subjects $(2.86 \pm 1.10 \mathrm{~cm} / \mathrm{s})$ were elevated compared to the control LV $(2.72 \pm 0.62 \mathrm{~cm} / \mathrm{s})$ and RV $(2.21 \pm 1.00 \mathrm{~cm} / \mathrm{s})$. Neonatal peak s' velocities were elevated in HLHS subjects $(3.05 \pm 0.93 \mathrm{~cm} / \mathrm{s})$ compared to the control LV $(2.14 \pm 0.61 \mathrm{~cm} / \mathrm{s})$ but not the RV $(3.19 \pm 1.02 \mathrm{~cm} / \mathrm{s})$.

Fetal ejection pressure difference was elevated in the HLHS subjects $(-0.94 \pm 0.71 \mathrm{mmHg})$ compared to the control LV $(-0.48 \pm 0.31 \mathrm{mmHg})$ and $\mathrm{RV}(-0.54 \pm 0.44 \mathrm{mmHg})$. The neonatal control ejection pressure difference increases for both the $\mathrm{LV}(-0.76 \pm 0.34 \mathrm{mmHg})$ and RV $(-0.74 \pm 0.28 \mathrm{mmHg})$ while the neonatal HLHS $(-0.61 \pm 0.80 \mathrm{mmHg})$ measurements do not change significantly. These metrics indicate that the HLHS right heart increases annular plane motion to efficiently eject blood in utero, overcoming the volume overload and increased vascular resistance, which would induce reduced myocardial contraction. 
medRxiv preprint doi: https://doi.org/10.1101/2020.10.21.20217265; this version posted June 22, 2021. The copyright holder for this preprint (which was not certified by peer review) is the author/funder, who has granted medRxiv a license to display the preprint in perpetuity.

\section{Diastolic function}

Increased e' velocity was observed in fetal HLHS subjects $(1.88 \pm 0.97 \mathrm{~cm} / \mathrm{s})$ as compared against the control LV $(1.23 \pm 0.81 \mathrm{~cm} / \mathrm{s})$ and RV $(1.19 \pm 0.57 \mathrm{~cm} / \mathrm{s})$. After birth, peak e' velocity for the control RV $(1.80 \pm 0.73 \mathrm{~cm} / \mathrm{s})$ increases compared to HLHS $(1.18 \pm 1.12 \mathrm{~cm} / \mathrm{s})$ and control LV $(1.26 \pm 0.50 \mathrm{~cm} / \mathrm{s})$ measurements. We observed peak a' velocities in fetal HLHS $(0.84 \pm 0.98 \mathrm{~cm} / \mathrm{s})$, control LV $(1.08 \pm 0.80 \mathrm{~cm} / \mathrm{s})$, and control RV $(0.85 \pm 0.82 \mathrm{~cm} / \mathrm{s})$ measurements were similar. Neonatal HLHS peak a' velocity $(1.36 \pm 0.57 \mathrm{~cm} / \mathrm{s})$ becomes elevated compared to control LV $(0.88 \pm 0.40 \mathrm{~cm} / \mathrm{s})$ and control RV $(1.17 \pm 0.74 \mathrm{~cm} / \mathrm{s})$. These metrics indicate that the heart adapts to efficiently relax but annular motion increases in late diastole to fill the HLHS right heart in the presence of reduced compliance.

Peak E velocity in the fetal HLHS subjects $(44.5 \pm 20.2 \mathrm{~cm} / \mathrm{s})$ was elevated compared to the fetal control LV $(25.5 \pm 13.2 \mathrm{~cm} / \mathrm{s})$ and RV $(30.5 \pm 20.8 \mathrm{~cm} / \mathrm{s})$. Neonatal control LV peak E velocity increases significantly $(58.8 \pm 17.6 \mathrm{~cm} / \mathrm{s})$ compared to HLHS $(64.8 \pm 23.7 \mathrm{~cm} / \mathrm{s})$ and control RV $(44.4 \pm 13.7 \mathrm{~cm} / \mathrm{s})$ measurements. Peak A velocity in the fetal HLHS subjects $(43.7 \pm 12.1 \mathrm{~cm} / \mathrm{s})$ was similar to the control $\mathrm{LV}(36.9 \pm 12.8 \mathrm{~cm} / \mathrm{s})$ and $\mathrm{RV}(37.3 \pm 11.3$ $\mathrm{cm} / \mathrm{s})$. After birth elevated peak A velocity was observed in the HLHS subjects $(66.9 \pm 23.0$ $\mathrm{cm} / \mathrm{s})$ compared to the control LV $(33.5 \pm 8.1 \mathrm{~cm} / \mathrm{s})$ and RV $(46.0 \pm 6.7 \mathrm{~cm} / \mathrm{s})$. These metrics indicate the HLHS right heart requires increased atrial contraction to fill the ventricle.

Suction $\Delta P$ was as similar across fetal HLHS $(0.31 \pm 0.34 \mathrm{mmHg})$, control LV $(0.19 \pm 0.16$ $\mathrm{cm} / \mathrm{s})$, and control RV $(0.24 \pm 0.36 \mathrm{~cm} / \mathrm{s})$ measurements. Neonatal HLHS suction $\Delta P$ significantly increases $(1.26 \pm 1.57 \mathrm{mmHg})$ compared to the control $\mathrm{LV}(0.27 \pm 0.18 \mathrm{mmHg})$ and RV $(0.56 \pm 1.11 \mathrm{mmHg})$. Recovery $\Delta P$ was elevated in fetal HLHS subjects $(-1.78 \pm 0.64$ $\mathrm{mmHg})$ compared to the control $\mathrm{LV}(-0.71 \pm 0.29 \mathrm{mmHg})$ and $\mathrm{RV}(-0.97 \pm 0.55 \mathrm{mmHg})$. Recovery $\Delta P$ increases for neonatal HLHS $(-1.97 \pm 1.35 \mathrm{mmHg})$, control LV $(-1.72 \pm 1.41$ $\mathrm{mmHg})$ and control RV $(-1.59 \pm 1.46 \mathrm{mmHg})$ measurements. AV-to- $\mathrm{P}_{\min }$ occurs further from the annular plane for the fetal HLHS right heart $(7.4 \pm 3.0 \mathrm{~mm})$ compared to the control LV $(5.4 \pm 2.7 \mathrm{~mm})$ and $\mathrm{RV}(6.1 \pm 2.3 \mathrm{~mm})$. This is maintained for the neonatal HLHS $(10.5 \pm 5.1$ $\mathrm{mm})$, control LV $(3.7 \pm 2.6 \mathrm{~mm})$, and control RV $(4.8 \pm 2.8 \mathrm{~mm})$. These metrics indicate that the HLHS right heart experiences greater pressure differences to achieve efficient filling.

Peak EL in fetal HLHS subjects $\left(0.35 \pm 0.19 \mathrm{~m}^{3} / \mathrm{s}^{2}\right)$ was elevated compared to the control LV $\left(0.09 \pm 0.07 \mathrm{~m}^{3} / \mathrm{s}^{2}\right)$ and RV $\left(0.17 \pm 0.12 \mathrm{~m}^{3} / \mathrm{s}^{2}\right)$. Neonatal HLHS $\left(0.55 \pm 0.24 \mathrm{~m}^{3} / \mathrm{s}^{2}\right)$ and 
medRxiv preprint doi: https://doi.org/10.1101/2020.10.21.20217265; this version posted June 22, 2021. The copyright holder for this preprint (which was not certified by peer review) is the author/funder, who has granted medRxiv a license to display the preprint in perpetuity.

control LV $\left(0.23 \pm 0.20 \mathrm{~m}^{3} / \mathrm{s}^{2}\right)$ peak EL increases while the control RV $\left(0.09 \pm 0.06 \mathrm{~m}^{3} / \mathrm{s}^{2}\right)$ is reduced. Peak VS in fetal HLHS subjects $\left(225 \pm 73 \mathrm{~cm}^{2} / \mathrm{s}\right)$ was elevated compared to the control LV $\left(77 \pm 38 \mathrm{~cm}^{2} / \mathrm{s}\right)$ and RV $\left(113 \pm 52 \mathrm{~cm}^{2} / \mathrm{s}\right)$. Neonatal HLHS $\left(345 \pm 74 \mathrm{~cm}^{2} / \mathrm{s}\right)$ and control LV $\left(137 \pm 83 \mathrm{~cm}^{2} / \mathrm{s}\right)$ peak VS increases while the control RV $\left(71 \pm 32 \mathrm{~cm}^{2} / \mathrm{s}\right)$ is reduced. These metrics indicate that the increased HLHS right heart area causes greater energy loss, reducing efficient redirection of the blood volume before systolic ejection.

\section{$\underline{\text { Discussion }}$}

This study quantified the biomechanics of ventricular function for normal and HLHS hearts from fetal and neonatal echocardiograms using new automated analysis methods. Our findings indicate that aside from typical HLHS RV remodeling, altered diastolic blood flow and reduced compliance occur. This is only realized with the integrated platform which assesses ventricular chamber morphology, deformation, and hemodynamics.

HLHS defects are readily identified with fetal ultrasound when the RV remodels to support the pulmonary and systemic circulations. While SV and CO differed significantly $(\mathrm{p}<0.05)$ between control and HLHS subjects, total SV between the fetal HLHS $(2.40 \mathrm{~mL})$ and control $(2.59 \mathrm{~mL})$ hearts, and between the neonatal HLHS $(4.50 \mathrm{~mL})$ and control $(4.81 \mathrm{~mL})$ hearts closely matched. These parameters enumerate remodeling but are readily observable by qualitative assessment.

The fetal HLHS RV s' $(\mathrm{p}<0.01)$ is increased compared to control subjects, an effect of volume overload which requires greater ejection of blood volume from the single ventricle compared to the bi-ventricle anatomy. The s' quantity remains unchanged after birth for the HLHS RV, indicating reduced compliance and increased stiffness. This is only found with speckle tracking measurements, which are just seeing clinical acceptance.

Reduced compliance is observable through the elevated pressure differences required to fill and empty the HLHS RV, which also contributes to the altered flow patterns. In the fetal condition, increased recovery and ejection pressure differences are present for the HLHS RV ( $p$ $<0.01$ ), which indicate added resistances. These differences diminish after birth, although suction and recovery pressure differences remain elevated. The accompanying altered flow patterns for the HLHS RV are the most sensitive, showing elevated energy loss and vortex strength in both fetal and neonatal conditions $(\mathrm{p}<0.01)$, indicating the formation of large, 
medRxiv preprint doi: https://doi.org/10.1101/2020.10.21.20217265; this version posted June 22, 2021. The copyright holder for this preprint (which was not certified by peer review) is the author/funder, who has granted medRxiv a license to display the preprint in perpetuity.

All rights reserved. No reuse allowed without permission.

energy-inefficient vortices. This work shows the first such application of CFI-based flow reconstruction using fetal imaging, offering new metrics for early detection of cardiac anomalies, and possibly altering the treatment course of the infant. Importantly, these new indices will allow better quantification of myocardial performance thus improving the diagnosis and management of fetal heart failure.

\section{Study limitations}

We treat each heartbeat as an independent observation, which potentially introduces bias into the reported means. Our cohort comprised 12 studies across 9 subjects, so investigating functional differences between conditions may not be sufficiently supported. Strain and strain rate, which are just gaining clinical acceptance, were not computed in this study. Imaging limitations in fetal echocardiography require novel strain measurement algorithms to be developed to ensure the most robust evaluation possible. Additional fetal and pediatric measurements would enable further quantification of functional differences.

\section{$\underline{\text { Conclusions }}$}

A new set of integrated, automated, vendor agnostic echocardiogram analysis methods is introduced for evaluating cardiac biomechanics from fetal and neonatal scans. This workflow enables clinically relevant measurements to be obtained more readily from a single scan, saving time, and reducing the need for specialized training. Importantly, no modification of image acquisition or scan technique was required to obtain these data. Our evaluation of HLHS and normal subjects supports the capabilities of our methods to provide reliable measurement from demonstratively challenging echocardiograms. Altered morphology, hemodynamics, and ventricular relaxation were observed in the presence of a severe CHD, indicating the methods can potentially provide earlier detection of anomalies in utero and may lead to improving treatment practices ex utero. 
medRxiv preprint doi: https://doi.org/10.1101/2020.10.21.20217265; this version posted June 22, 2021. The copyright holder for this preprint (which was not certified by peer review) is the author/funder, who has granted medRxiv a license to display the preprint in perpetuity.

\section{$\underline{\text { References }}$}

1. Hamilton BE, Osterman MJK, Driscoll AK, Rossen LM, Martin JA, Osterman MJK, et al. Births: Provisional data for 2017. NVSS Vital Stat Rapid Release. 2018;2(002):1-21.

2. Benjamin EJ, Virani SS, Callaway CW, Chamberlain AM, Chang AR, Cheng S, et al. Heart disease and stroke statistics-2018 update: a report from the American Heart Association. Circulation. 2018;137(12):e67-492.

3. Arth AC, Tinker SC, Simeone RM, Ailes EC, Cragan JD, Grosse SD. Inpatient hospitalization costs associated with birth defects among persons of all ages-United States, 2013. MMWR Morb Mortal Wkly Rep. 2017;66(2):41.

4. Gilboa SM, Salemi JL, Nembhard WN, Fixler DE, Correa A. Mortality resulting from congenital heart disease among children and adults in the United States, 1999 to 2006. Circulation. 2010;122(22):2254-63.

5. Tworetzky W, McElhinney DB, Reddy VM, Brook MM, Hanley FL, Silverman. NH. Improved Surgical Outcome After Fetal Diagnosis of Hypoplastic Left Heart Syndrome. Circulation. 2001;103(9):1269-73.

6. Huhta JC, Paul JJ. Doppler in fetal heart failure. Clin Obstet Gynecol. 2010;53(4):915-29.

7. Todros T, Capuzzo E, Gaglioti P. Prenatal diagnosis of congenital anomalies. Images Paediatr Cardiol. 2001;3(2):3.

8. Donofrio MT, Moon-Grady AJ, Hornberger LK, Copel JA, Sklansky MS, Abuhamad A, et al. Diagnosis and treatment of fetal cardiac disease: a scientific statement from the American Heart Association. Circulation. 2014;129(21):2183-242.

9. Rychik J, Ayres N, Cuneo B, Gotteiner N, Hornberger L, Spevak PJ, et al. American society of echocardiography guidelines and standards for performance of the fetal echocardiogram. J Am Soc Echocardiogr. 2004;17(7):803-10. 
medRxiv preprint doi: https://doi.org/10.1101/2020.10.21.20217265; this version posted June 22, 2021. The copyright holder for this preprint (which was not certified by peer review) is the author/funder, who has granted medRxiv a license to display the preprint in perpetuity. All rights reserved. No reuse allowed without permission.

10. Marini D, van Amerom J, Saini BS, Sun L, Seed M. MR imaging of the fetal heart. J Magn Reson Imaging. 2020;51(4):1030-44.

11. Schrauben EM, Saini BS, Darby JRT, Soo JY, Lock MC, Stirrat E, et al. Fetal hemodynamics and cardiac streaming assessed by 4D flow cardiovascular magnetic resonance in fetal sheep. J Cardiovasc Magn Reson. 2019;21(1):8.

12. Lai WW, Geva T, Shirali GS, Frommelt PC, Humes RA, Brook MM, et al. Guidelines and Standards for Performance of a Pediatric Echocardiogram: A Report from the Task Force of the Pediatric Council of the American Society of Echocardiography. J Am Soc Echocardiogr. 2006;19(12):1413-30.

13. Haruki N, Takeuchi M, Gerard O, Nakai H, Dufour C, Denis E, et al. Accuracy of measuring mitral annular velocity by 2D speckle tracking imaging. J Cardiol. 2009;53(2):188-95.

14. Schoonderwaldt EM, Groenenberg IALL, Hop WCJJ, Wladimiroff JW, Steegers EAPP. Reproducibility of echocardiographic measurements of human fetal left ventricular volumes and ejection fractions using four-dimensional ultrasound with the spatio-temporal image correlation modality. Eur J Obstet Gynecol Reprod Biol. 2012;160(1):22-9.

15. DeVore GR, Klas B, Satou G, Sklansky M. Evaluation of Fetal Left Ventricular Size and Function Using Speckle $\square$ Tracking and the Simpson Rule. J Ultrasound Med. 2019;38(5):1209-21.

16. Lopez L, Colan SD, Frommelt PC, Ensing GJ, Kendall K, Younoszai AK, et al. Recommendations for quantification methods during the performance of a pediatric echocardiogram: a report from the Pediatric Measurements Writing Group of the American Society of Echocardiography Pediatric and Congenital Heart Disease Council. J 
medRxiv preprint doi: https://doi.org/10.1101/2020.10.21.20217265; this version posted June 22, 2021. The copyright holder for this preprint

(which was not certified by peer review) is the author/funder, who has granted medRxiv a license to display the preprint in perpetuity.

All rights reserved. No reuse allowed without permission.

Am Soc Echocardiogr. 2010;23(5):465-95.

17. Dijkstra EW. A note on two problems in connexion with graphs. Numer Math. 1959;1(1):269-71.

18. Donofrio MT, Moon-grady AJ, Hornberger LK, Copel JA, Sklansky MS, Abuhamad A, et al. Diagnosis and Treatment of Fetal Cardiac Disease. Circulation. 2014;129(21):2183242.

19. Meyers BA, Goergen CJ, Segers P, Vlachos PP. Colour-Doppler echocardiography flow field velocity reconstruction using a streamfunction-vorticity formulation. J R Soc Interface. 2020;17(173):20200741.

20. Raffel M, Willert CE, Kompenhans J. Particle image velocimetry: a practical guide. 2007.

21. Friemel BH, Bohs LN, Trahey GE. Relative performance of two-dimensional speckletracking techniques: normalized correlation, non-normalized correlation and sumabsolute-difference. Proc IEEE Ultrason Symp. 1995;2:1481-4.

22. Jeong J, Hussain F. On the identification of a vortex. J Fluid Mech. 1995;285:69-94.

23. Zhang J, Brindise MC, Rothenberger S, Schnell S, Markl M, Saloner D, et al. 4D Flow MRI Pressure Estimation Using Velocity Measurement-Error based Weighted LeastSquares. IEEE Trans Med Imaging. 2019; 


\section{$\underline{\text { Appendix A }}$}

\section{Speckle Tracking Algorithm}

Input atrioventricular valve (AV) annulus ends at the septal and lateral walls positions and the ventricle apex position are tracked temporally using Fourier domain cross-correlation ${ }^{20,21}$. Between sequential frames a sub-window of pixels centered around each position is taken. Each spatial sub-window pair, $w_{1}(x, y)$ and $w_{2}(x, y)$, is converted to the Fourier domain via the Fast Fourier Transform (FFT),

$G_{i}(u, v)=\mathcal{F}\left(w_{i}(x, y)\right)$.

Equation A.1

The Fourier Transforms for each pair are subsequently cross correlated,

$R(x, y)=\mathcal{F}^{-1}\left(G_{1}(u, v) \bar{G}_{2}(u, v)\right)$

Equation A.2

where $\mathcal{F}^{-1}$ is the inverse Fourier Transform $(\mathrm{FT}),(u, v)$ are wavenumbers proportional to spatial coordinates $(x, y)$, and the overbar symbolizes the complex conjugate. The displacement between the pair is computed by the peak location of the cross-correlation $R$

$$
(\Delta x, \Delta y)=\operatorname{argmax}_{(x, y)}(R) \text {, }
$$

Equation A.3

Each position is updated by adding the displacements to the current positions, which are then used as new centers for the next sub-window pair in the temporal image sequence.

\section{Unsupervised Segmentation Algorithm}

Identifying the ventricle boundary with the unsupervised segmentation algorithm occurs in four steps: (1) image pre-processing, (2) pathfinding with Dijkstra's algorithm using an echocardiogram specific cost-matrix, (3) post-processing, and (4) volume calculation.

Image pre-processing works to normalize the contrast-to-noise ratio (CNR), smooth added image noise, and transform the image onto a polar grid. These steps improve the reliability of the Dijkstra's algorithm in segmenting the boundary. Image CNR normalization uses adaptive contrast enhancement, which is computed for each image pixel,

$\operatorname{Im}_{A C E}(x, y)=\frac{\operatorname{Im}(x, y)-I m_{a v g}}{I m_{\max }-I m_{\text {avg }}}$.

Equation A.4

In Equation A.4, $I m_{A C E}$ is the ACE pixel intensity, $I m$ is the raw pixel intensity, $I m_{a v g}$ is the average pixel intensity of a line from the AV valve ends to the ventricle apex, and $I m_{\max }$ is the maximum intensity in the entire image. Median filtering with an $11 \mathrm{x} 11$ pixel window is used to smooth the noise. The polar transformation, last in the image pre-processing, warps the image 
medRxiv preprint doi: https://doi.org/10.1101/2020.10.21.20217265; this version posted June 22, 2021. The copyright holder for this preprint (which was not certified by peer review) is the author/funder, who has granted medRxiv a license to display the preprint in perpetuity.

from a Cartesian grid $(x, y)$ to a polar grid $(\rho, \theta)$ relative to the center of the ventricle $\left(x_{c}, y_{c}\right)$, using the equations,

$\rho=\sqrt{\left(x-x_{c}\right)^{2}+\left(y-y_{c}\right)^{2}}, \theta=\operatorname{atan}\left(\frac{y}{x}\right)$.

Equation A.5

By transforming the ventricle image, the curve or pathfinding of the ventricle simplifies the search for a curve that connects the two AV valve nodes through the ventricle apex. A costmatrix for the performing the Dijkstra's algorithm is constructed by initially treating each pixel as a graph-node. A peak prominence- -based cost was chosen; in this approach along each line of $\theta$ the local peak intensities $(\hat{I})$ and their height compared to the local minimum $\widehat{(P)}$ are computed, which are used in the cost equation $(C)$

$C=15(\hat{P}+\hat{I})^{-1}$.

Equation A.6

To reduce computation time, nodes larger than 1.25 the mean of $C$ are discarded. The Dijkstra's algorithm ${ }^{17}$ was used iteratively, allowing the method to detect the lowest cost for a limited number of lines of $\theta$. This step size was varied from $2^{\circ}$ to $14^{\circ}$ in steps of $2^{\circ}$. The seven curves generated from the iterative processing were fit with a smoothing-spline radial basis function to produce a single representative curve, or the ventricle segmentation. This segmentation is converted back onto a Cartesian grid.

Each curve is post-processed with a boundary smoothing tool to ensure the segmentation appears physiologically consistent. This post-processing finds all possible paths within a neighborhood of nodes in the curve, evaluates the gradients for all paths and the current path, selects the path with the smallest gradient. Two iterations are performed to ensure no oversmoothing occurs.

\section{Doppler Vector Reconstruction Algorithm}

The color Doppler vector reconstruction algorithm used in this work is based on the relationship between the flow rate and fluid rotation. The algorithm processes a single-color Doppler frame by (1) converting the color signal to velocities, (2) segmenting the ventricle from the gray-scale signal and imposing boundary conditions, and (3) using a numerical solver to reconstruct the velocity field.

For each color Doppler recording, the user inputs the AV annulus end positions and ventricle apex position from the first recorded frame like the algorithms above. The user will also crop the velocity color scale from the first recorded frame and provide its upper and lower velocity limits, 
medRxiv preprint doi: https://doi.org/10.1101/2020.10.21.20217265; this version posted June 22, 2021. The copyright holder for this preprint (which was not certified by peer review) is the author/funder, who has granted medRxiv a license to display the preprint in perpetuity.

in centimeters per second. A velocity range the same length as the color velocity scale is constructed.

A single frame is first separated into a color-signal image and a gray-scale image. This step avoids adding noise in further calculations and ensures only the blood flow signal is used in the reconstruction. Each pixel in the color-signal is converted to a velocity by converting its color value on the image velocity color scale to a velocity on the constructed velocity range. The output is a map of velocity measurements that correspond to the color-signal of the current color Doppler frame.

The gray-scale image is evaluated using the unsupervised segmentation algorithm and the current AV annulus end positions and apex position to obtain a segmentation curve. This curve is converted to a binary mask with the same dimensions as the map of velocity measurements. Velocity measurements along a line between the AV annulus end positions are used to impose inflow/outflow conditions for the solver,

$\Psi_{\text {flow }}(s)=\int_{s_{0}}^{s_{a}} u(s) d \xi+\psi_{0}$.

Equation A.7

In equation $7, \psi_{0}$ is the initial flow rate which we set to zero, $\psi_{\text {flow }}$ is the flow rate a location along the line $s$, and $s_{0}$ and $s_{a}$ are the annulus end positions of the line. A freepenetration condition is assumed along the ventricle walls to ensure flow rate is balanced, which is assumed to be linearly distributed,

$\psi_{\text {wall }}(s)=f(s, u)$.

Equation A.8

The Doppler Vector Reconstruction (DoVeR) solver is used to reconstruct the 2D velocity vector field ${ }^{19}$ using the boundary conditions and map of velocities. An initial fluid rotation source term, $\omega^{0}$, is quantified. An initial error is provided, set to be infinite. DoVeR is an iterative reconstruction tool, so the error is checked against a threshold for each iteration; this threshold was set to $10^{-8}$. The error is computed from the L2-norm of the difference between the current and previous iteration reconstructed vector fields,

$\varepsilon=\frac{\left\|\mathbf{u}^{n}-\mathbf{u}^{n-1}\right\|}{\left\|\mathbf{u}^{n}\right\|}$.

Equation A.9

So long as error is not minimized the iteration number, $n$, is increased and new flow rates through the ventricle $\psi^{n}$ are computed from the fluid rotation $\omega^{n-1}$ by LU-decomposition of, $\ddot{D} \psi^{n}=-\omega^{n-1}$, Equation A.10 
medRxiv preprint doi: https://doi.org/10.1101/2020.10.21.20217265; this version posted June 22, 2021. The copyright holder for this preprint (which was not certified by peer review) is the author/funder, who has granted medRxiv a license to display the preprint in perpetuity.

All rights reserved. No reuse allowed without permission.

where $\ddot{\boldsymbol{D}}$ is the second-order derivative operator of size $N \times N$ with a 3-point stencil size, and $\omega^{n-1}$ and $\psi^{n}$ are $N \times 1$ vectors. The quantity $N$ is the total number of points within the ventricle boundary. The reconstructed $2 \mathrm{D}$ velocity vector field, $\mathbf{u}^{n}$, is computed with,

$\mathbf{u}^{\boldsymbol{n}}=\left[\begin{array}{ll}\mathrm{u}_{x}^{n} & \mathrm{u}_{y}^{n}\end{array}\right]=\left[\begin{array}{ll}\dot{\boldsymbol{D}}_{\boldsymbol{y}} \psi^{n} & \dot{\boldsymbol{D}}_{\boldsymbol{x}} \psi^{n}\end{array}\right]$,

Equation A.11

where $\dot{\boldsymbol{D}}_{\boldsymbol{x}}$ and $\dot{\boldsymbol{D}}_{\boldsymbol{y}}$ are first-order derivative operators of size $N \times N$ with 3-point stencil size for derivatives in $x$ and $y$. All non-zero velocities from the input velocity map must remain constant in $\mathrm{u}_{y}^{n}$ to further constrain the solver. Zero velocities from the input velocity map can be replaced but are threshold to $\pm 10 \%$ of the maximum of the input velocity map. Finally, the fluid rotation $\omega^{n}$ is updated using the discrete formulation,

$\omega^{n}=\dot{\boldsymbol{D}}_{x} \mathrm{u}_{y}^{n}-\dot{\boldsymbol{D}}_{\boldsymbol{y}} \mathrm{u}_{x}^{n}$

Equation A.12

\section{Reconstruction post-processing}

Post-processing the reconstructed 2D vector fields (Figure 1e) helps quantify ventricle flow efficiency. The vector fields are quantified using finite-differencing. Flow energy loss (EL) is calculated by,

$$
\begin{array}{r}
E L=\int\left[2\left(\frac{\partial u_{x}}{\partial x}\right)^{2}+2\left(\frac{\partial u_{y}}{\partial y}\right)^{2}\right. \\
\left.+\left(\frac{\partial u_{x}}{\partial y}+\frac{\partial u_{y}}{\partial x}\right)^{2}\right] d V
\end{array}
$$

Equation A.13

where $V$ is the volume of the region of flow, found by multiplying the 2D area of the ventricle by the AV valve diameter. Vortices are identified based on flow rotation, using the $\lambda_{\mathrm{CI}}$ criterion $^{22}$. The total vortex strength (VS) from this algorithm is,

$$
V S=\sum\left|\int \omega d A\right|_{\text {vortex }}
$$

Equation A.14

where $A$ is the area of each identified vortex. The subscript indicates summation across all identified vortex structures. The 2D pressure field, $P$, inside the ventricles is computed using the pressure Poisson equation,

$$
\nabla^{2} P=\left(\frac{\partial u_{x}}{\partial x}\right)^{2}+\left(\frac{\partial u_{y}}{\partial y}\right)^{2}+2\left(\frac{\partial u_{x}}{\partial y} \frac{\partial u_{y}}{\partial x}\right)
$$

Equation A.15

Neumann boundary conditions account for temporal variation of pressure. The solver reconstructs $P$ using a least squares formulation, through an in-house algorithm ${ }^{23}$. This analysis 
medRxiv preprint doi: https://doi.org/10.1101/2020.10.21.20217265; this version posted June 22, 2021. The copyright holder for this preprint (which was not certified by peer review) is the author/funder, who has granted medRxiv a license to display the preprint in perpetuity.

All rights reserved. No reuse allowed without permission.

returns quantities for peak early and late AV valve velocities (E,A), EL, VS, and peak suction and reversal $\mathrm{AV}$ valve-to-apex pressure differences $(\Delta P)$.

\section{$\underline{\text { Appendix B }}$}

In complement to Figure 3, timeseries analysis of intraventricular pressure differences and peak filling velocity waveforms are provided for each condition. These results demonstrate how the abnormal HLHS geometry can alter filling patterns.

Filling of healthy hearts for a fetus at 33-weeks gestation and at 0 weeks old, provided in Figure B.5, shows similar filling function in early life. Two distinct phases of diastolic filling, early and late, can be observed in the velocity waveforms of these subjects. In the fetal subject, vortex rings are observed in both early diastole (Figure B.5a-3) and late diastole (Figure B.5a-4), forming along the exterior of the filling inflow jet near the AV valves. These features help aid with efficient filling of the cardiac chambers. Similar features are observed in the 0 -weeks old baby in both early diastole (Figure B.5b-3) and late diastole (Figure B.5b-4), though less pronounced, possibly due to scan alignment being shifted from the AV valve center.

Filling of the HLHS heart for a single subject at 33-weeks gestation and 0 weeks old, provided in Figure B.6, shows how filling changes when unassisted breathing begins. Both timepoints show only one distinct filling phase, which may indicate either fusion of the two phases, or the flow is purely atrial driven. At 33-weeks gestation, a single large vortex forms along the inflow jet during both early diastole (Figure B.6a-3) and late diastole (Figure B.6a-4). At 0 weeks old, no prominent vortex features can be observed in early diastole (Figure B.6b-3) or late diastole (Figure B.6b-4). 
medRxiv preprint doi: https://doi.org/10.1101/2020.10.21.20217265; this version posted June 22, 2021. The copyright holder for this preprint (which was not certified by peer review) is the author/funder, who has granted medRxiv a license to display the preprint in perpetuity. All rights reserved. No reuse allowed without permission.

Figure 1: Echocardiogram analysis workflow. Analysis begins with the user providing A4C views. (1) AV annulus and apex feature points are provided to initialize automated analysis. (2) $B$-mode frames are evaluated to find pixel costs and paths for ventricle segmentation and volume quantification. (3) Color Doppler frames are processed to extract the signal, segment the ventricle, set initial conditions, and reconstruct velocity fields. Cardiac function measurements are compiled into a workflow report.

Figure 2: Ventricle volumes (1-3) measured from the LV and RV of a normal (a) fetal heart and $a(b)$ neonatal heart as well as the RV from an HLHS patient from a $(c)$ fetal heart exam and (d) neonatal heart exam.

Figure 3: Vector reconstruction of flow in the $L V$ and $R V$ of a healthy $(a-1,2)$ fetal heart and $(a-3,4)$ neonatal heart and flow in the RV of an HLHS subject from $a(b-1,2)$ fetal exam and $a(b$ 3,4) neonatal heart exam during diastolic filling and systolic ejection. Vectors are overlaid onto energy loss estimates. Pressure reconstructions are provided for the (c) healthy and (d) HLHS subjects. Closed contours (green) correspond to vortices.

Figure 4: Measurements from fetal and neonatal scans used to assess ventricular function in healthy and HLHS patients. The p-values provided are between healthy left and right ventricle measurements and between each healthy ventricle and HLHS right ventricles, along with pvalues across the prenatal and postnatal age groups for both conditions.

Figure B.5: Velocity vector fields overlaid on estimated pressure contours for the healthy heart of (a) a fetus at 33-weeks gestation and (b) a baby at 0 weeks old.

Figure B.6:Velocity vector fields overlaid on estimated pressure contours for the single ventricle heart of (a) a fetus at 33-weeks gestation and (b) a baby at 0 weeks old. 


\section{Workflow \\ Initialization}

User-provided recordings

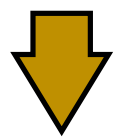

1. User input point tracking

2. Cost evaluation and path finding

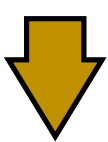

3. Signal extraction and initialization

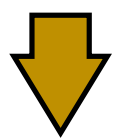

Workflow Report
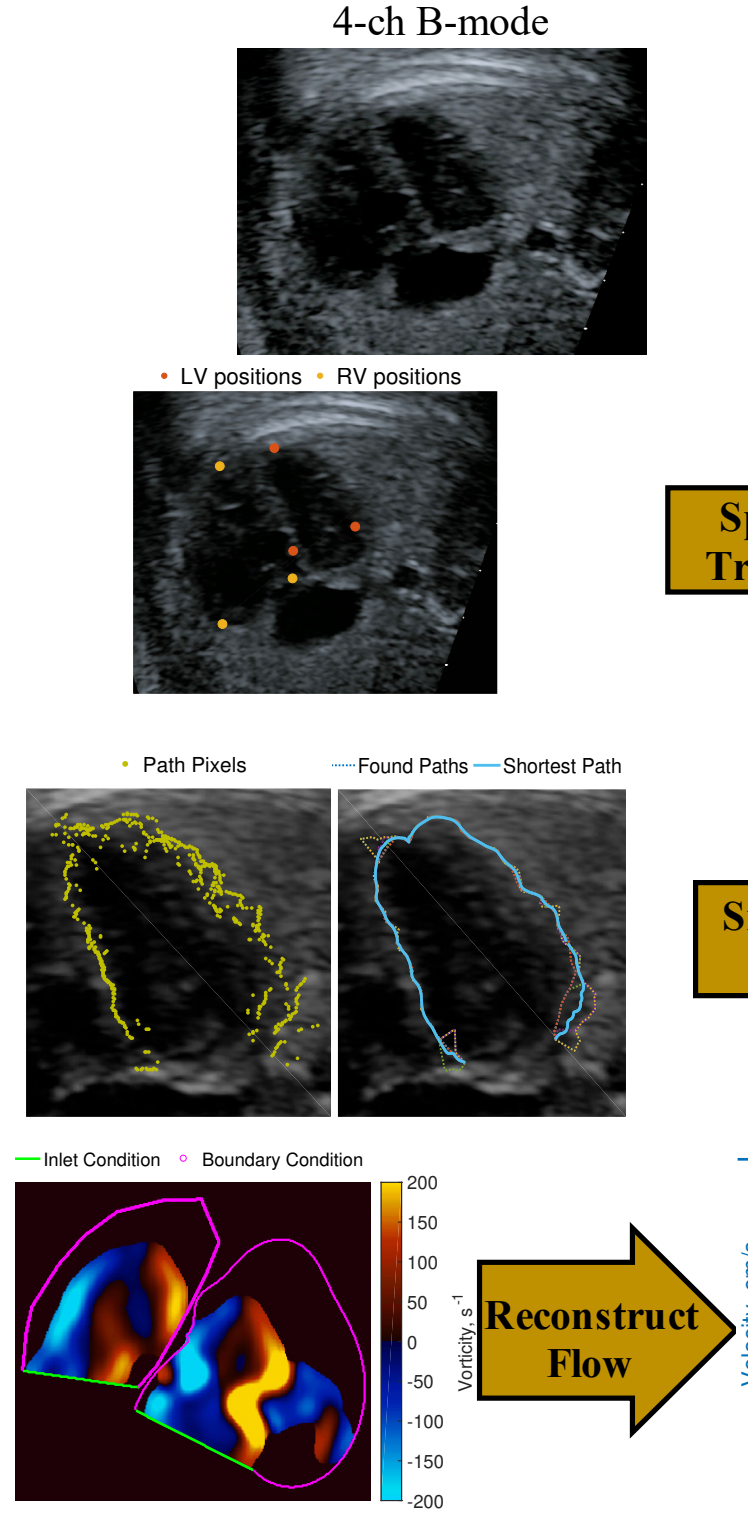

Left Ventricle Function measurements

$\mathrm{E}(\mathrm{cm} / \mathrm{s}): 39$

A $(\mathrm{cm} / \mathrm{s}): \mathrm{N} / \mathrm{A}$ $\Delta \mathrm{P}(\mathrm{mmHg})$

Suction: 0.06

Recovery: -0.45

Ejection: -0.11 4-ch Color Doppler
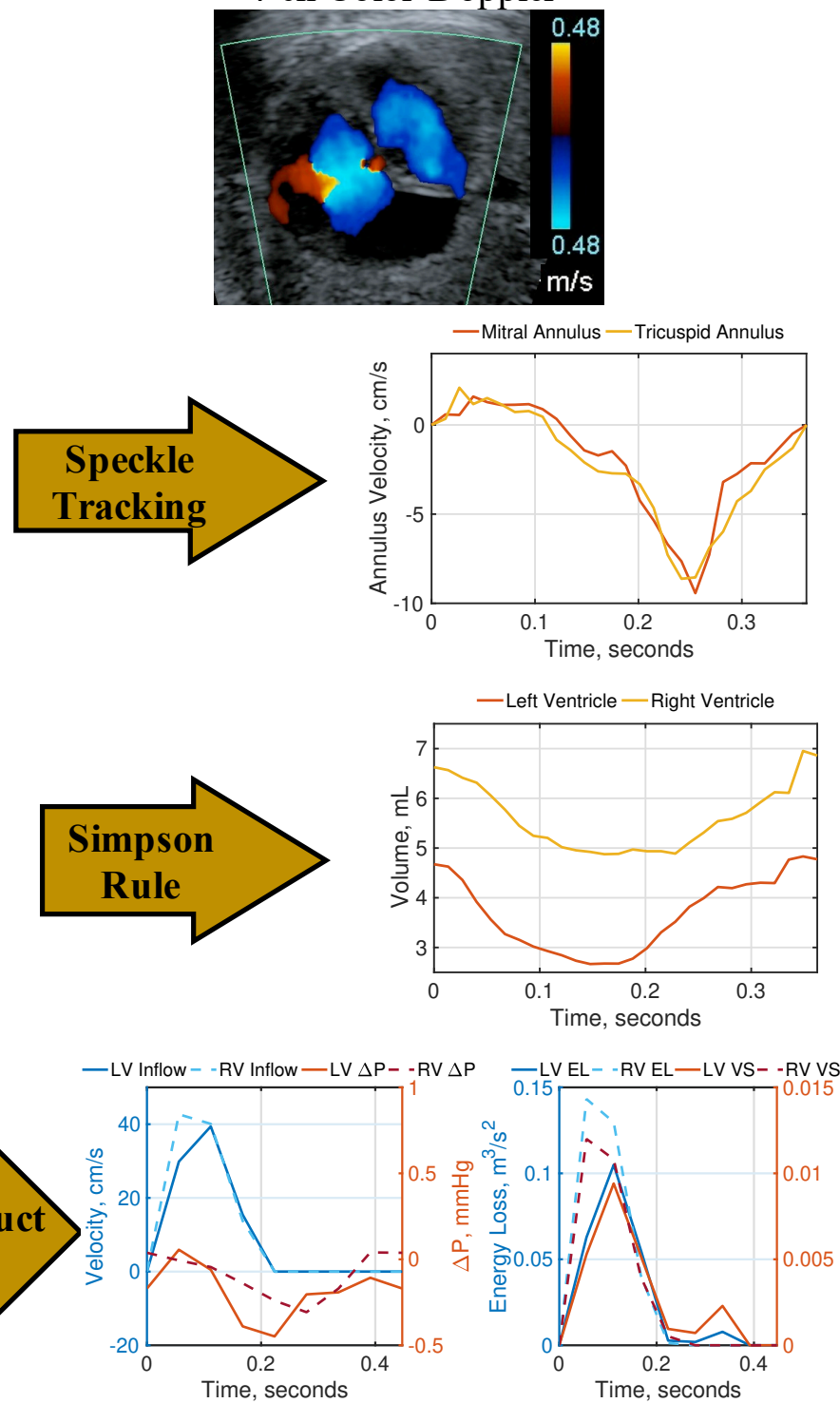

Right Ventricle Function measurements
$\mathrm{EL}\left(\mathrm{m}^{3} / \mathrm{s}^{2}\right): 0.10$

$\mathrm{VS}\left(\mathrm{m}^{2} / \mathrm{s}\right): 0.010$

$\mathrm{SV}(\mathrm{ml}): 2.0$

|s' $(\mathrm{cm} / \mathrm{s}): 1.6$

e' $(\mathrm{cm} / \mathrm{s}):-8.6$
E (cm/s): 43

A $(\mathrm{cm} / \mathrm{s}):$ N/A $\Delta \mathrm{P}(\mathrm{mmHg})$

Suction: 0.04

Recovery: -0.31

Ejection: 0.04
$\mathrm{EL}\left(\mathrm{m}^{3} / \mathrm{s}^{2}\right): 0.14$

$\mathrm{VS}\left(\mathrm{m}^{2} / \mathrm{s}\right): 0.012$

$\mathrm{SV}(\mathrm{ml}): 2.0$

$\mathrm{s}^{\prime}(\mathrm{cm} / \mathrm{s}): 2.1$

e' $(\mathrm{cm} / \mathrm{s}):-9,4$

$a^{\prime}(\mathrm{cm} / \mathrm{s}):$ N/A 


\section{Diastolic Filling Systolic Ejection Diastolic Filling}

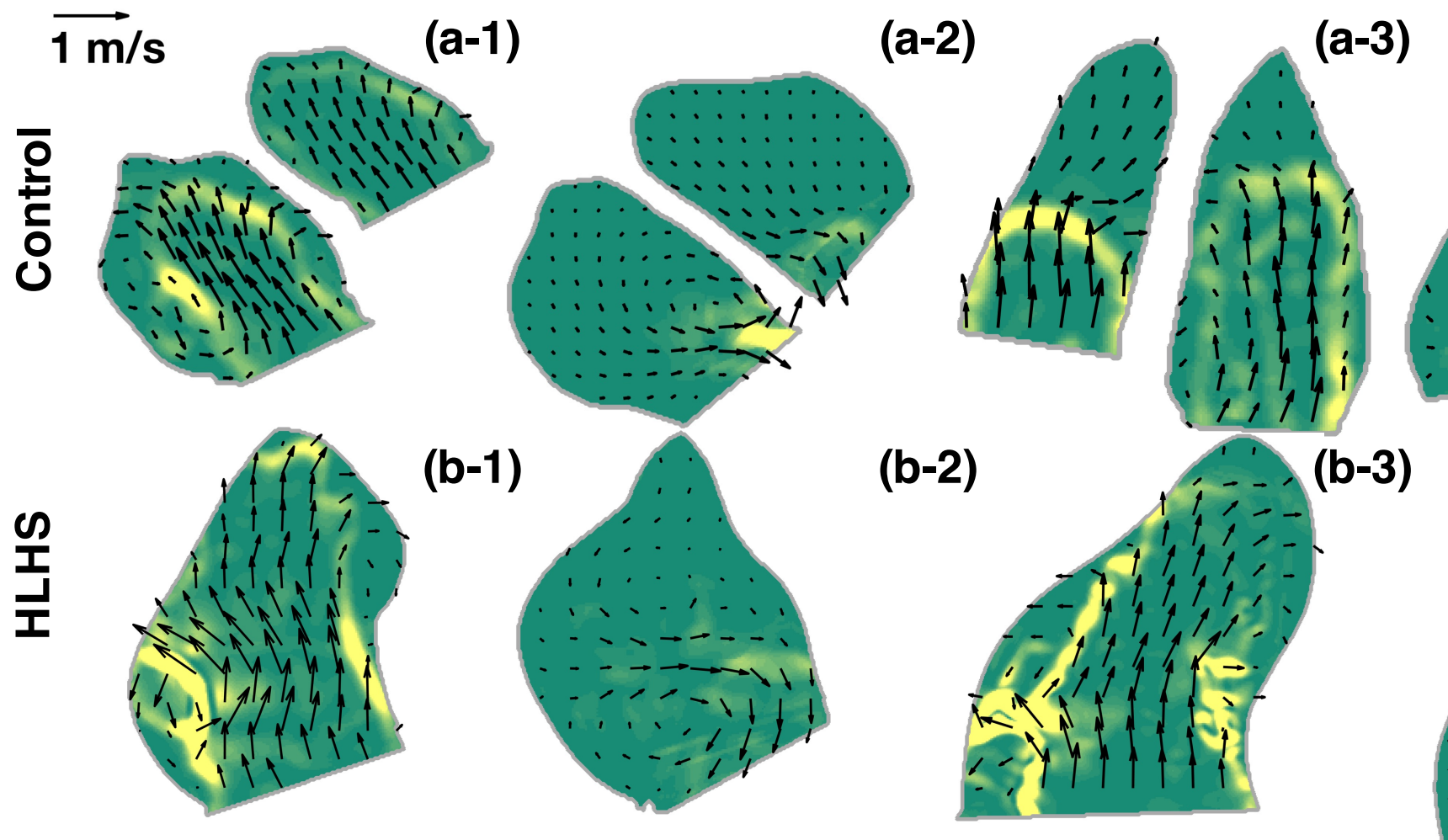

\section{Systolic Ejection}

(a-2)
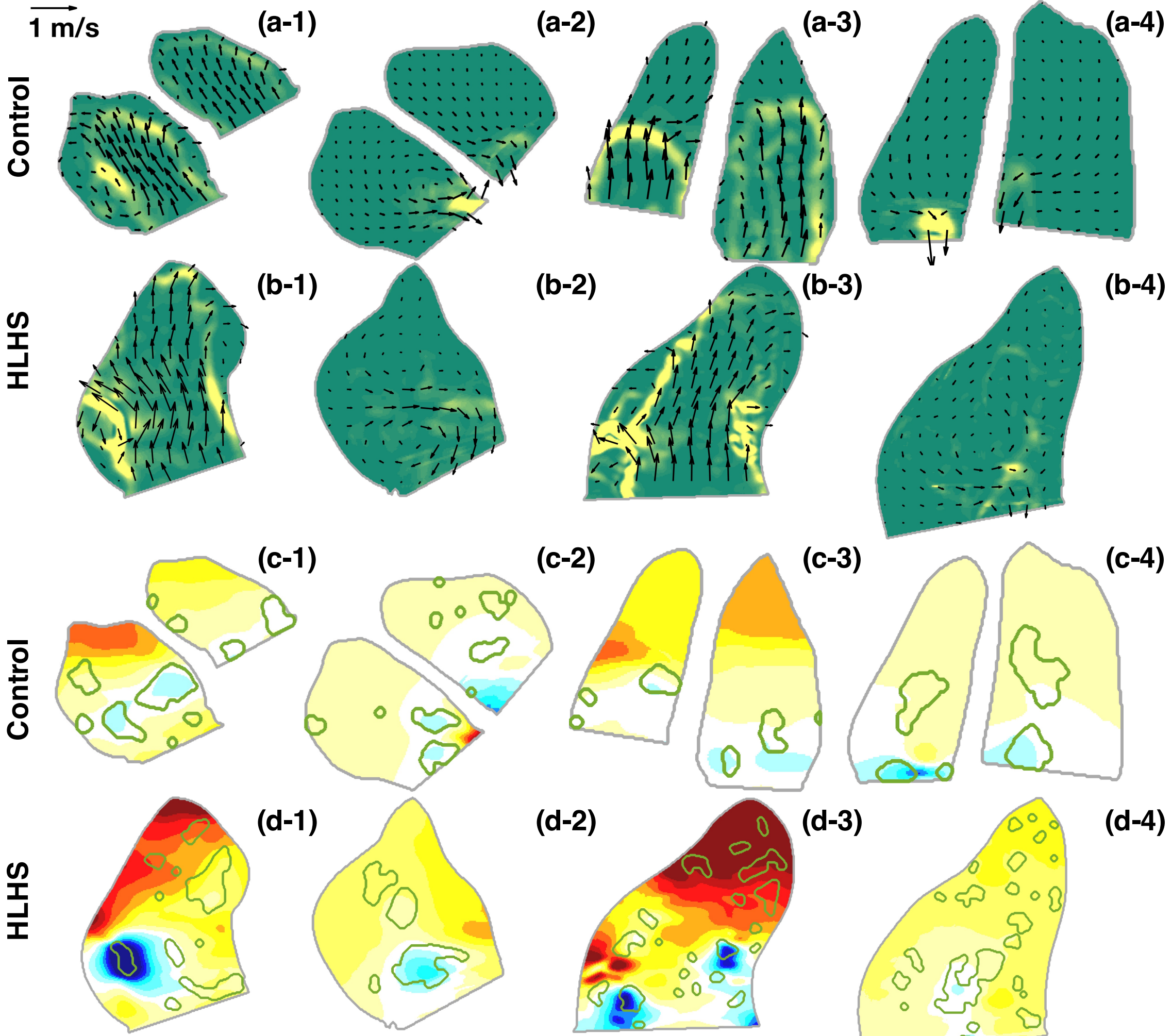

$(d-1)$

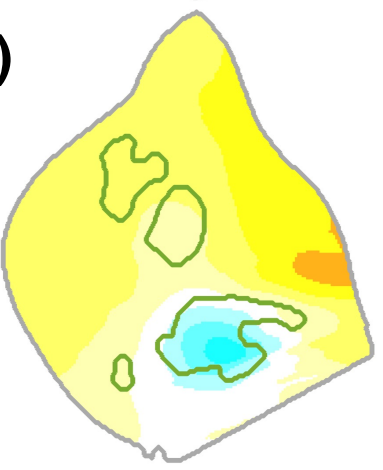

(c-2)

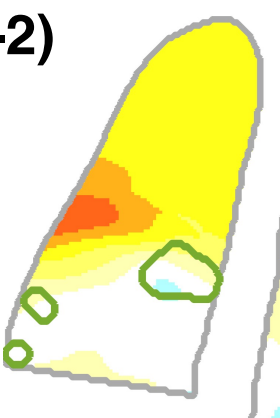

(d-2)

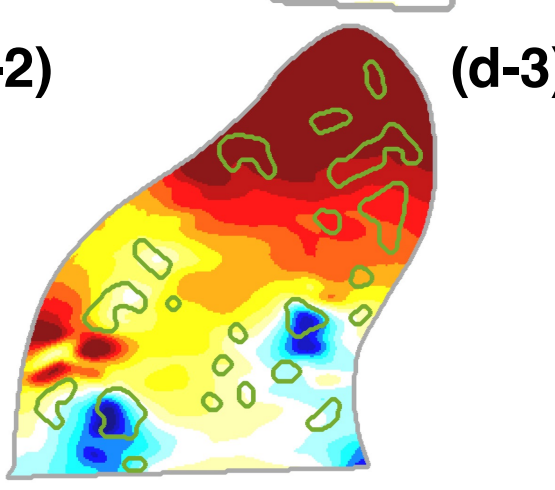

(c-3)

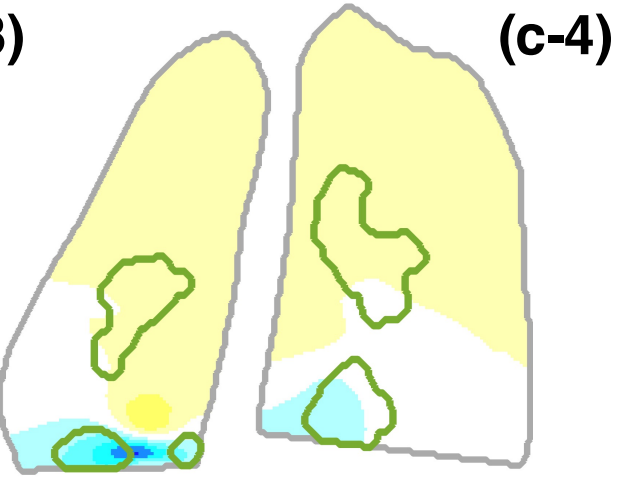

$(d-4)$

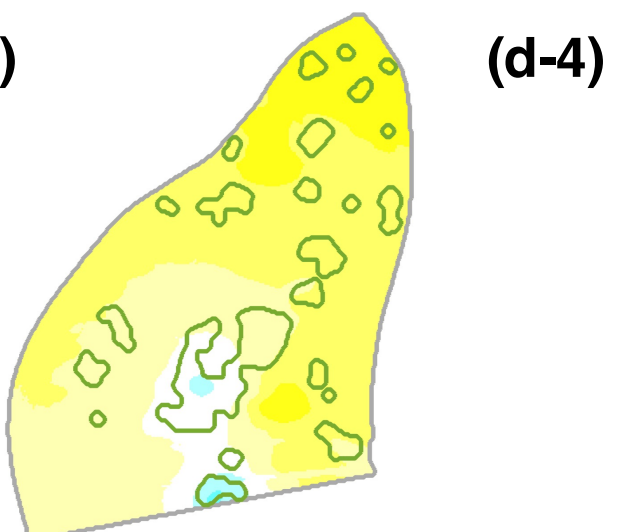

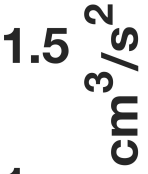

10

?우

0.5 تُ

\section{5}

1

$\begin{array}{ll}0.5 & \frac{0}{1} \\ 0 & \frac{9}{\varepsilon} \\ -0.5 & \end{array}$

$-1$

$-1.5$ 


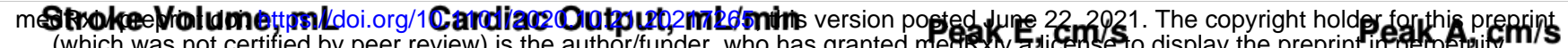
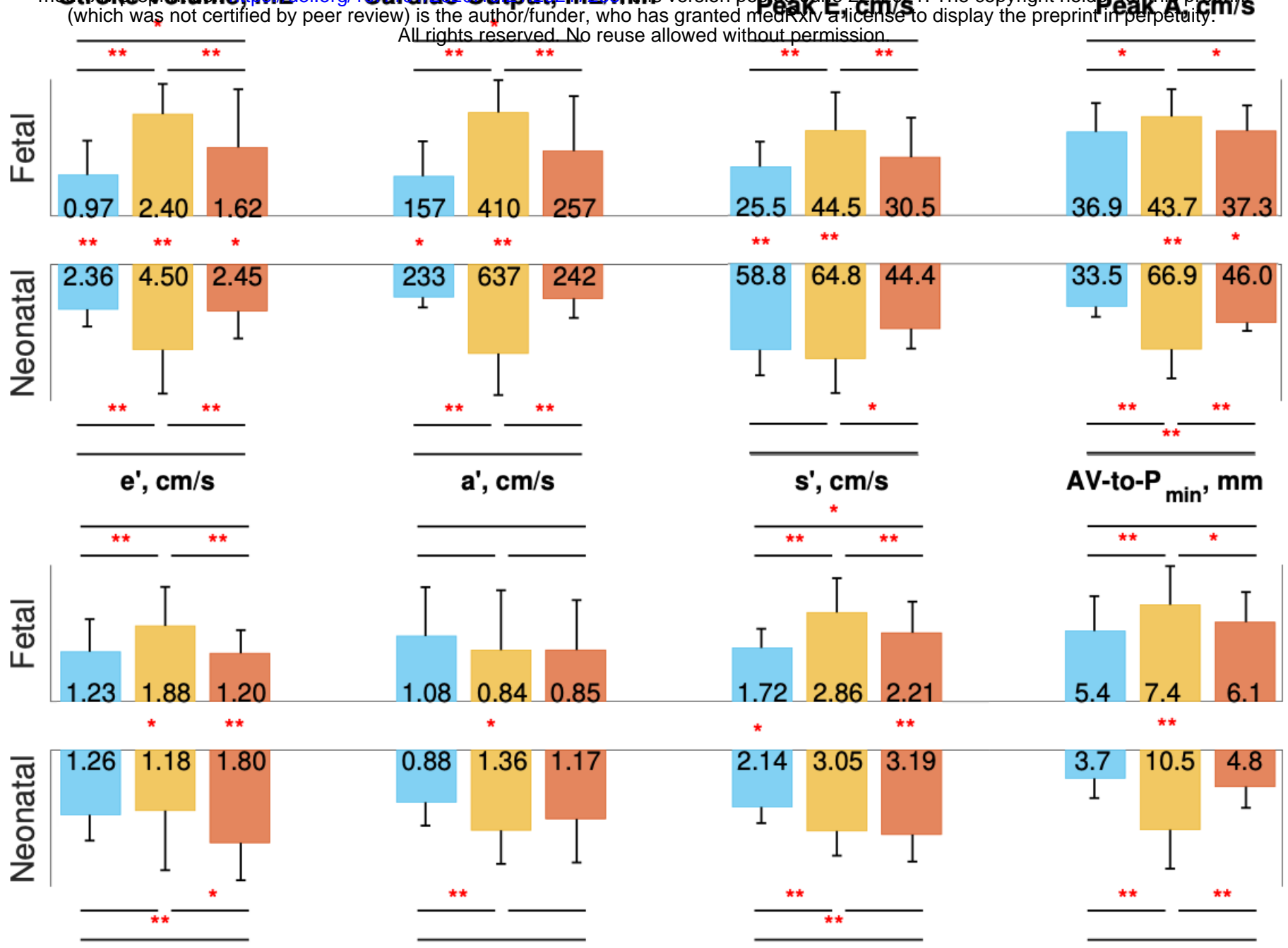

Suction $\Delta \mathrm{P}, \mathrm{mmHg}$
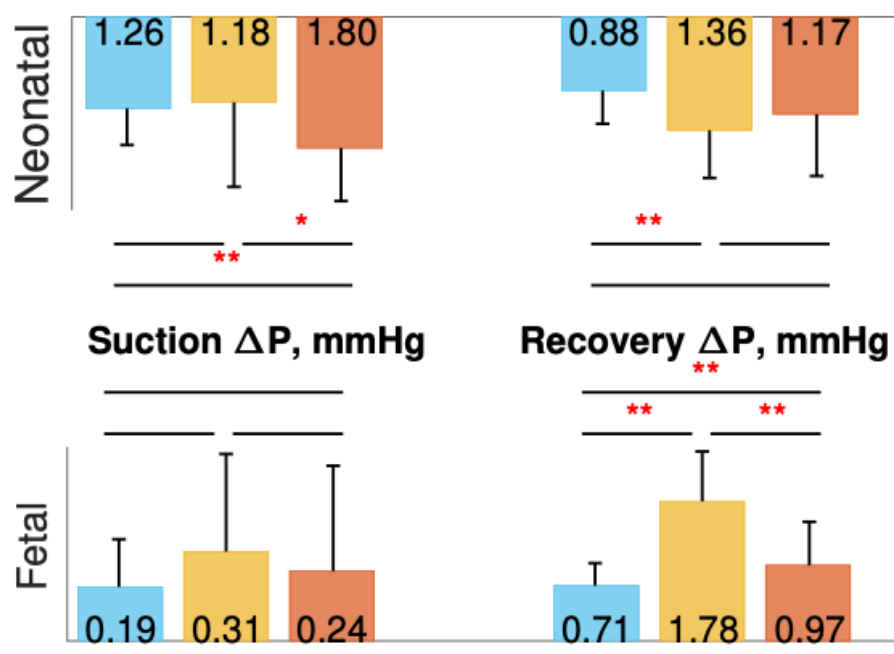

\section{Ejection $\Delta \mathbf{P}, \mathrm{mmHg}$}
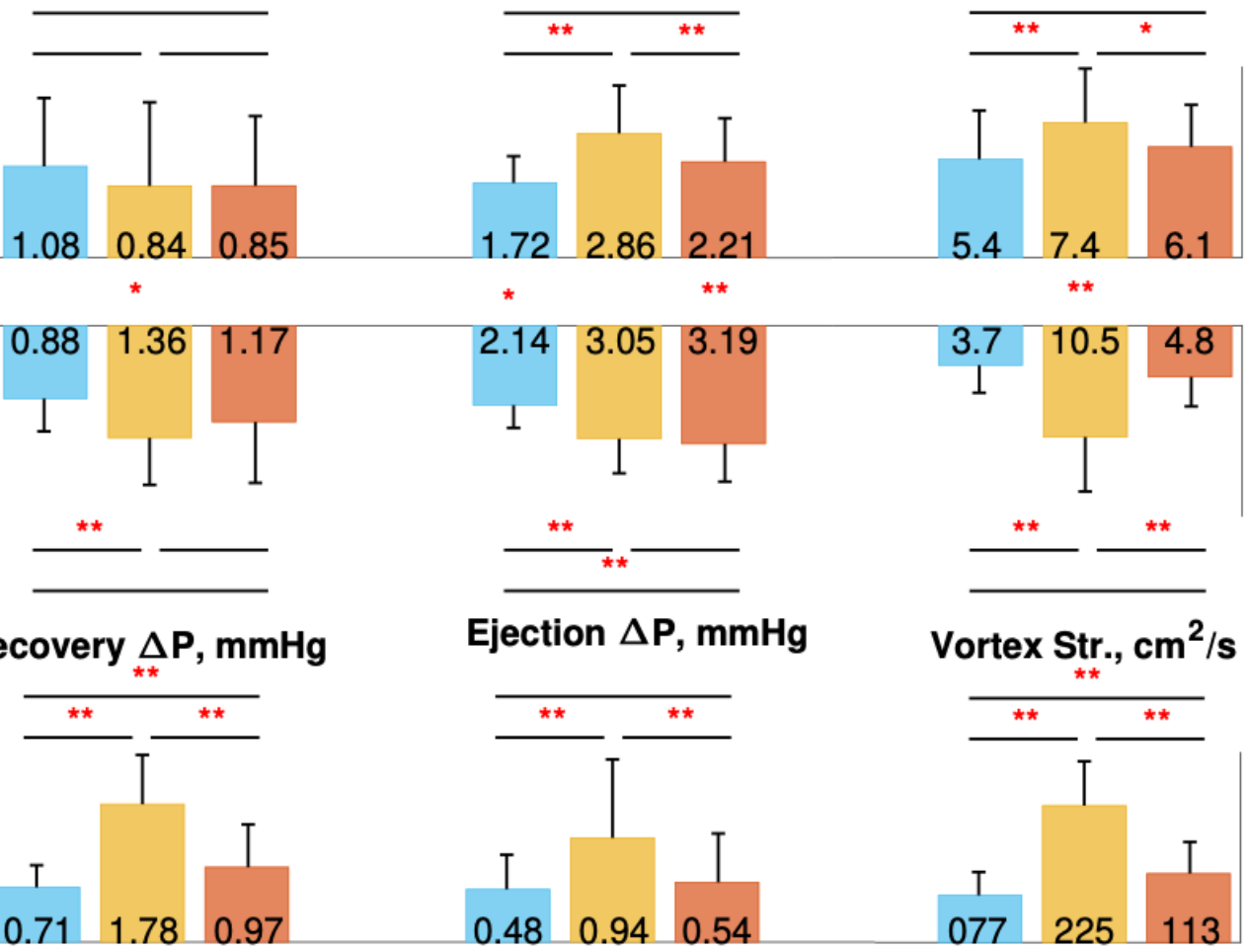

Vortex $\underset{* \star}{\mathrm{Str} .}, \mathrm{cm}^{2} / \mathrm{s}$
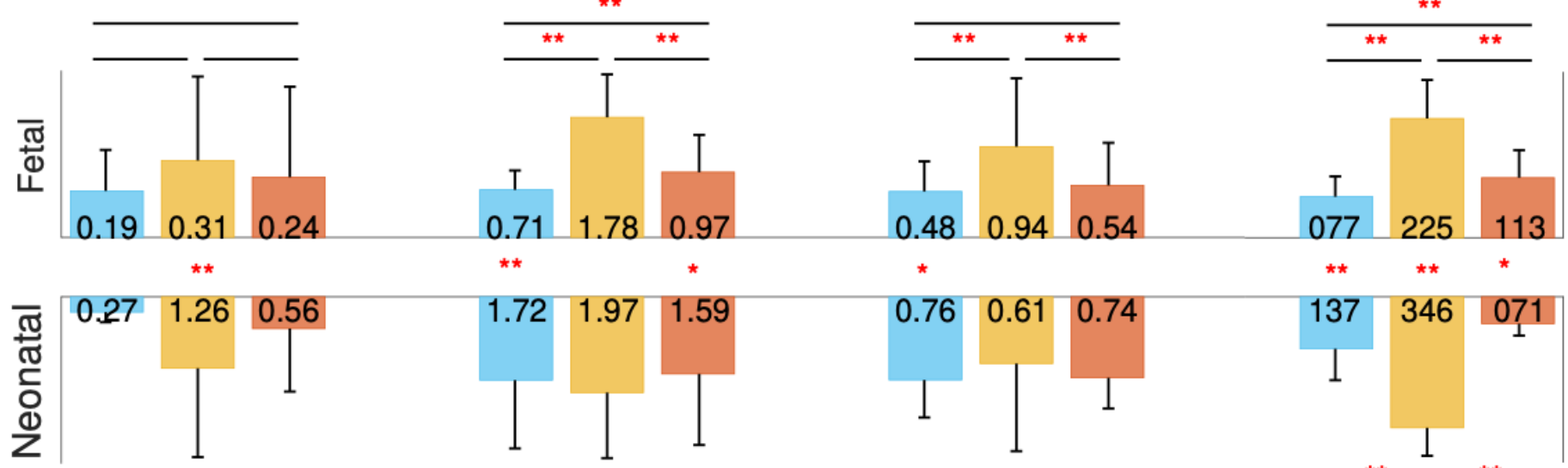

Energy Loss, $\mathrm{m}^{3} / \mathrm{s}^{2}$

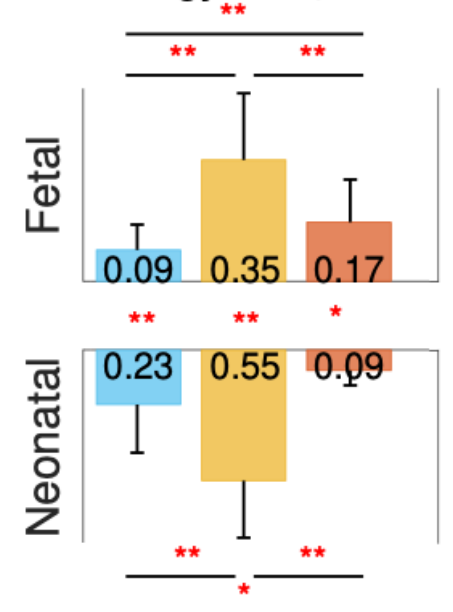

Control LV

HLHS RV

Control RV

I $+/-1 \sigma$ 


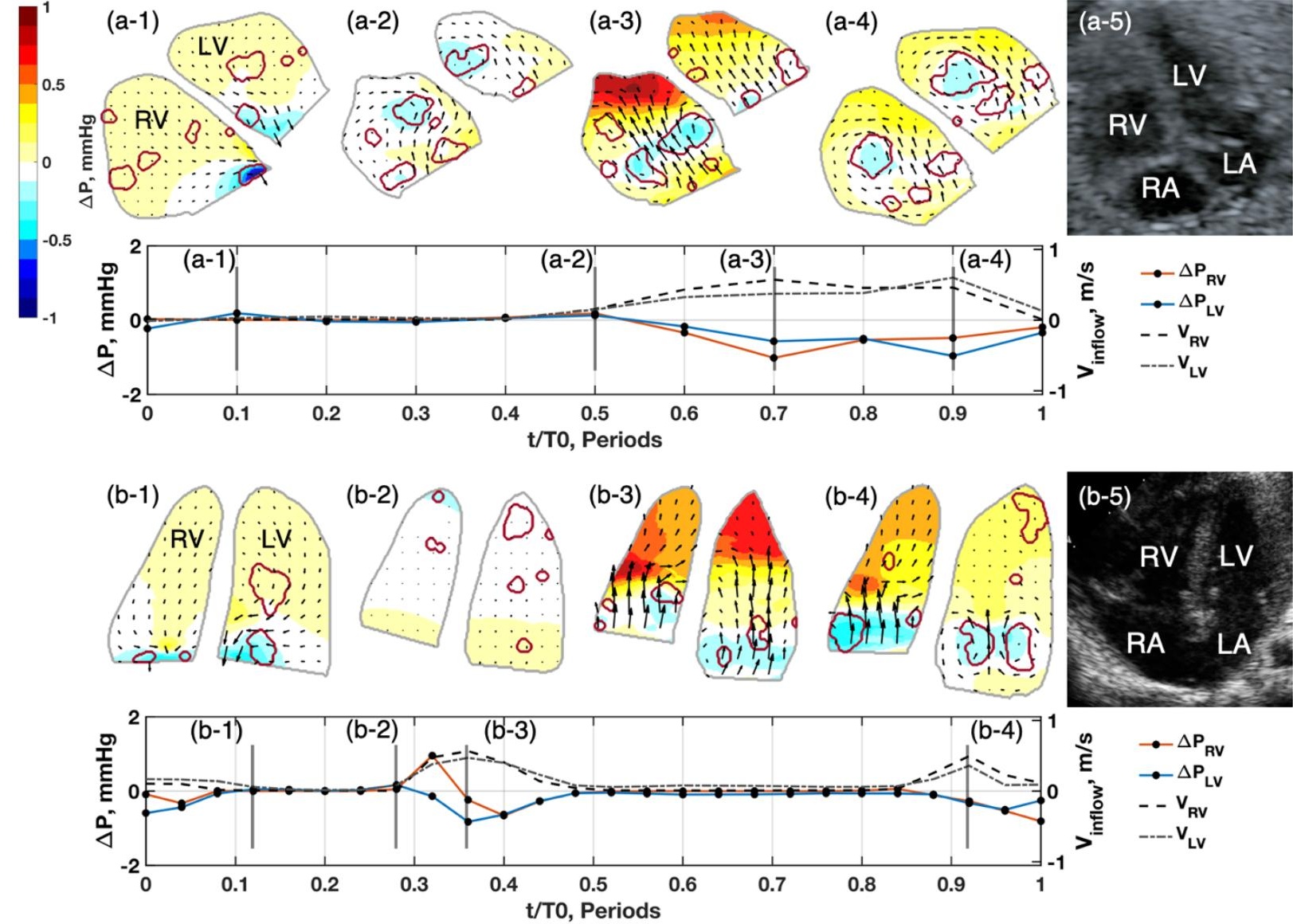


